and nuclear translocation of NF- $\mathrm{KB}$ by immunofluorescence. Differences between experimental groups were evaluated by ANOVA followed by Tukey post-test.

Results $60-80 \%$ and $30-50 \%$ of the RA FLS tested expressed TNFRI and TNFRII, respectively, and $7-10 \%$ expressed HVEM. In comparison with non-stimulated cells, LT $\alpha$ induced proliferation 4-fold, such as TNF $\alpha$. LT $\alpha$ - and TNF $\alpha$-induced proliferation was significantly blocked by etanercept. Both LT $\alpha$ and TNF $\alpha$ induced phosphorylation, thus activation of MAP kinases ERK $1 / 2$ and p38 as well as Akt. Specific inhibitors for the MAP and PI3 kinases blocked proliferation induced by LT $\alpha$ and TNF $\alpha .95-98 \%$ of RA FLS showed nuclear translocation of NF- $\kappa \mathrm{B}$ after stimulation with either cytokine. Both LT $\alpha$ and TNF $\alpha$ were potent to induce secretion of interleukin (IL)6, IL8 and metalloproteinase-3 in RA FLS.

Conclusions LT $\alpha$ is as effective as TNF $\alpha$ in stimulating RA FLS. Blocking both cytokines might allow a better control of inflammation and synovial proliferation observed in RA.

This work was supported by Wyeth and GERIR.

\title{
A154 LYMPHOTOXIN $\alpha$ STIMULATES PROLIFERATION AND PROINFLAMMATORY CYTOKINE SECRETION OF RHEUMATOID ARTHRITIS FIBROBLAST-LIKE SYNOVIOCYTES
}

F Calmon Hamaty, M Hahne, B Combe, J Morel Institut de Génétique Moléculaire de Montpellier, France

\subsection{6/ard.2010.129650e}

Background and Purpose Lymphotoxin $\alpha(L T \alpha)$ is a proinflammatory cytokine with structural homology with tumour necrosis factor $\alpha(T N F \alpha)$. Both cytokines bind to the receptors TNFRI and TNFRII, and LT $\alpha$ also binds to the herpes virus entry mediator (HVEM). Increased LT $\alpha$ levels have been detected in patients with rheumatoid arthritis (RA), but its role in RA is poorly characterised. To elucidate its role in comparison with TNF $\alpha$, we analysed the effect of LT $\alpha$ in cultured RA fibroblast-like synoviocytes (FLS).

Methods RA FLS were extracted from synovial tissues of patients who met the ACR criteria for RA (revised 1987). Surface expression of receptors was analysed by FACS. Cells were stimulated with $0.5 \mathrm{nM} \mathrm{LT} \alpha$ or TNF $\alpha$ for $24 \mathrm{~h}$ and apoptosis was measured by annexin-V/TOPRO-3. After $72 \mathrm{~h}$ of stimulation, proliferation was evaluated by measuring DNA synthesis through incorporation of tritiated $[3 \mathrm{H}]$ thymidine and secretion of inflammatory cytokines by ELISA. Activation of MAP kinases and Akt was analysed by western blotting 